\title{
Alfvén waves in the near-PSBL lobe: Cluster observations
}

\author{
T. Takada ${ }^{1}$, R. Nakamura ${ }^{1}$, W. Baumjohann ${ }^{1}$, K. Seki ${ }^{2}$, Z. Vörös ${ }^{1}$, Y. Asano ${ }^{1}$, M. Volwerk ${ }^{1,3}$, A. Runov ${ }^{1}$, T. L. Zhang ${ }^{1}$, \\ A. Balogh ${ }^{4}$, G. Paschmann ${ }^{3}$, R. B. Torbert ${ }^{5}$, B. Klecker ${ }^{3}$, H. Rème ${ }^{6}$, P. Puhl-Quinn ${ }^{5}$, P. Canu ${ }^{7}$, and P. M. E. Décréau ${ }^{8}$ \\ ${ }^{1}$ Space Research Institute, Austrian Academy of Sciences, A-8042 Graz, Austria \\ ${ }^{2}$ Solar-Terrestrial Environment Laboratory, Nagoya University, Nagoya 464-8601, Japan \\ ${ }^{3}$ Max-Planck-Institut für extraterrestrische Physik, D-85741 Garching, Germany \\ ${ }^{4}$ Imperial College, London SW7 2BZ, UK \\ ${ }^{5}$ University of New Hampshire, Durham, NH 03824, USA \\ ${ }^{6}$ CESR/CNRS, F-31028 Toulouse Cedex 4, France \\ ${ }^{7}$ CETP/CNRS and VSQP University, F-78140 Vélizy, France \\ ${ }^{8}$ LPCE/CNRS and Université d'Orléans, F-45071 Orléans Cedex 2, France
}

Received: 17 September 2005 - Revised: 20 January 2006 - Accepted: 8 March 2006 - Published: 19 May 2006

\begin{abstract}
Electromagnetic low-frequency waves in the magnetotail lobe close to the PSBL (Plasma Sheet Boundary Layer) are studied using the Cluster spacecraft. The lobe waves show Alfvénic properties and transport their wave energy (Poynting flux) on average toward the Earth along magnetic field lines. Most of the wave events are rich with oxygen $\left(\mathrm{O}^{+}\right)$ion plasma. The rich $\mathrm{O}^{+}$plasma can serve to enhance the magnetic field fluctuations, resulting in a greater likelihood of observation, but it does not appear to be necessary for the generation of the waves. Taking into account the fact that all events are associated with auroral electrojet enhancements, the source of the lobe waves might be a substorm-associated instability, i.e. some instability near the reconnection site, or an ion beam-related instability in the PSBL.
\end{abstract}

Keywords. Magnetospheric physics (Magnetotail; MHD waves and instabilities; Storms and substorms)

\section{Introduction}

The magnetotail lobe is an empty region, where the magnetic field is stronger and the plasma density is lower than in the neighboring magnetosheath and plasma sheet (e.g. Stern, 1979). Only a few studies have reported ULF waves in the lobe, i.e. Pc4-Pc5 waves (45-s to 10-min periods) (e.g. Chen and Kivelson, 1991). The plausible sources of lobe waves are either an outer source, such as the global Kelvin-Helmholtz Instability (KHI) at the magnetopause (Smith et al., 1990; Sarafopoulos and Sarris, 1994), or an inner source, such as

Correspondence to: T. Takada

(taku.takada@oeaw.ac.at) compressional waves in the plasma sheet. As for an outer source, Sarafopoulos (1995) reported a good correlation between ULF waves and the solar wind dynamic pressure in an event study. As a case for an inner source, Elphinstone et al. (1995) presented IMP 8 observations of fast mode waves in the lobe, which appeared to be propagating earthward from a source located tailward of $X \sim-28 R_{E}$. Keiling et al. (2005) recently reported Polar observations of substormassociated lobe Alfvén waves at geocentric distances of 5 $6 R_{E}$. Some theories about Alfvén resonance coupling in the PSBL assume waves propagating through the lobe, supposedly generated by an outer source (Smith et al., 1986; Harrold et al., 1990; De Keyser, 2000) or an inner source (Liu et al., 1995; Allan and Wright, 1998, 2000). More abundant and enhanced waves are observed in the PSBL (e.g. Tsurutani et al., 1985; Akimoto et al., 1987; Angelopoulos et al., 1989). Takada et al. (2005) statistically examined the low-frequency waves in the tail PSBL between $X=(-15$, $-31) R_{E}$ and suggested that the waves are Alfvénic and are possibly generated locally by ion-beam related instabilities. Those PSBL waves are also considered to be the source of large-amplitude Alfvén waves observed by Polar in the nearEarth PSBL at geocentric distances of 4-6 $R_{E}$ (e.g. Wygant et al., 2000). Due to the existence of higher frequency electric field fluctuations, the electric-to-magnetic field fluctuations fit to the dispersion relation of kinetic Alfvén waves (KAW) in the Polar orbit (Wygant et al., 2002) and also at Geotail distances of $X \sim-18 R_{E}$ (Angelopoulos et al., 2002).

The magnetotail lobe maps to the high latitude polar cap regions on the Earth. Ground observations sometimes show ULF pulsations in the regions of open field lines. Weatherwax et al. (1997) reported a relation between Pc5 pulsations and cosmic radio noise absorption, i.e. precipitating energetic

Published by Copernicus GmbH on behalf of the European Geosciences Union. 


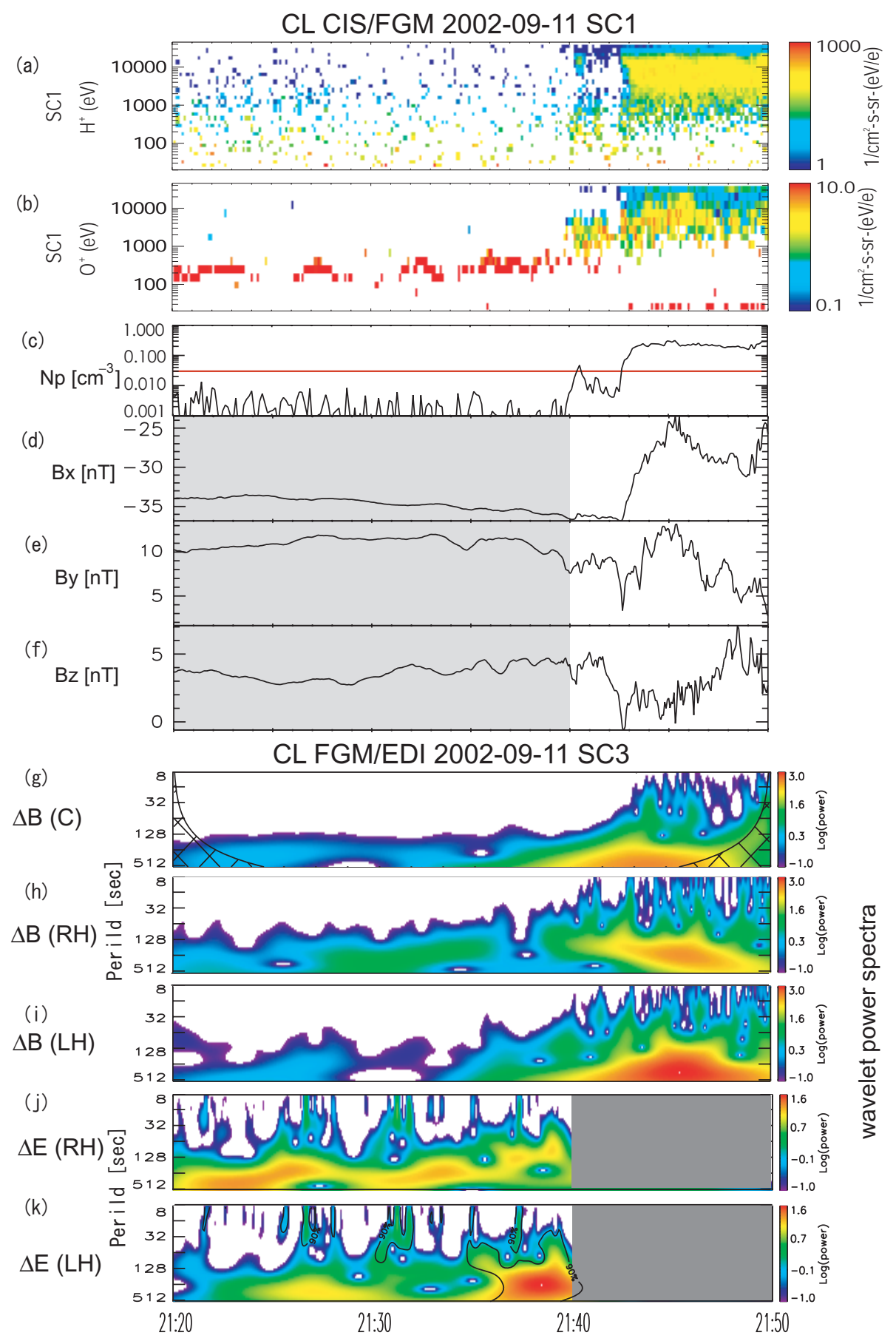

Fig. 1. Cluster observation on 11 September 2002. Energy-time diagram of (a) protons and (b) $\mathrm{O}^{+}$, (c) proton density, (d-f) magnetic field components in aberrated GSM coordinates (SC1). Red line in (c) indicate $N_{P}=0.03 \mathrm{~cm}^{-3}$ for statistical criteria. Wavelet power spectra of (gi) magnetic field fluctuations and (j-k) electric field fluctuations (SC 3) are shown in color scales. Each panel corresponds to compressional (C), right-hand $(\mathrm{RH})$ and left-hand ( $\mathrm{LH})$ components, respectively. Cross-hatched regions on either end indicate the "cone of influence" where edge effects become important (not shown in h, i, j, k, but same as g). Gray shaded areas in (d-f) are lobe region and shown in detail in Fig. 2. Gray shaded areas in $(\mathrm{j}-\mathrm{k})$ are the intermittent data lack intervals of EDI.

electrons. Most of the pulsations are closely related to the cusp (Ballatore et al., 1998) or the auroral electrojet (Pillipenko et al., 2001). Yagova et al. (2004) recently reported that some Pc5 pulsations at high latitude stations were independent of the cusp and auroral activities. Therefore, no conclusive generation mechanism of those pulsations yet exists. 
Thus, there are possibly two source regions considered for lobe waves. Of particular interest is whether substormassociated (Keiling et al., 2005) Alfvén waves in near-Earth can also be identified in a more distant region, which is closer to the reconnection sites. In this study the magnetic/electric field fluctuations in the near-PSBL lobe at $\mathrm{X}=(-6,-20) R_{E}$ are analyzed in detail. The Cluster orbit during the summer season leads to lobe/PSBL crossings close to the observed reconnection sites. In Sect. 2, a lobe wave event on 11 September 2002 is investigated in detail and the statistical properties of lobe waves are shown by examining 10 selected events. Then we discuss the characteristics of lobe waves and their relation with waves in other regions, for example, PSBL and ground polar cap.

We mainly use the data obtained by the FluxGate Magnetometer (FGM) instrument (Balogh et al., 2001) of the Cluster Spacecraft (SC) 1-4, the Electron Drift Instrument (EDI, Paschmann et al., 2001) of SC 1 and 3, and the COmposition and DIstribution Function analyser (CODIF) of the Cluster Ion Spectrometry experiment (CIS) (Rème et al., 2001) of SC 1, 3 and 4. All data throughout the paper are shown in the Aberrated Geomagnetic Solar Magnetospheric (AGSM) system, which is aligned with the solar wind flow $\left(\sim 4^{\circ}\right)$.

\section{Observation}

We have studied the wave characteristics of 10 events of lobe magnetic field fluctuation. The events are selected during July to October 2001 and 2002, when the apogee of Cluster was in the nightside magnetotail. The criteria for the event selection are the following: $X<-6 R_{E},|Y|<10 R_{E}$, and electric field data from the EDI instrument should be available on at least one spacecraft. The density criteria for the lobe, $N_{P}<0.03 \mathrm{~cm}^{-3}$ (see, e.g. the red line in Fig. 1c), is set to exclude boundary and mantle plasma. Our data set does not include dense lobe plasma (e.g. Sauvaud et al., 2004). The magnetic field fluctuations ( $\boldsymbol{B}_{0} \sim 5$-min moving average) should have a peak-to-peak amplitude of more than $1 \mathrm{nT}$ and last at least $5 \mathrm{~min}$ within $30 \mathrm{~min}$ before/after a lobe/PSBL crossing. The 5-min time window is chosen to remove any weak structure-associated trend, but to keep distinct wavelike fluctuations with periods of more than $5 \mathrm{~min}$. Note that we do not use any $\mathrm{O}^{+}$information for selection.

\subsection{Lobe wave characteristics: 11 September 2002 event}

One lobe fluctuation event is analyzed in detail in this subsection. As shown in Fig. 1, Cluster is located first in the lobe at $(X, Y, Z)=(-18.0,4.1,-5.0) R_{E}$, crosses the plasma sheet (PS)-lobe boundary at 21:40 UT and then enters into the plasma sheet at $\sim 21: 43$ UT. In the lobe (gray shaded area) $\mathrm{O}^{+}$beams from the ionosphere are clearly observed (Seki et al., 1998, and references therein). The magnetic field is almost stable in the lobe and strongly fluctuates in the PSBL/PS. However, wavelet spectra of both magnetic and perpendicular electric fluctuations in the lobe clearly show a right-hand mode enhancement at periods of $\sim 2-5 \mathrm{~min}$. Right-hand mode fluctuations appeared from 21:27 UT with gradually increasing periods (decreasing frequencies). A weak left-hand mode actually appears around 21:25 UT and another left-hand mode appears again after 21:36 UT. Although the polarization depends on each interval, the transverse components are generally dominant in the lobe, as in PSBL waves (Bauer et al., 1995). Another interesting point is that the spectra of electric field fluctuations seem to be overlapped with short period (high frequency) components. After the PS-lobe boundary crossing, magnetic fluctuations, such as magnetic noise bursts, are enhanced and broadened into the wide frequency ranges in the PSBL/PS (e.g. Cattell et al., 1986). In the PSBL/PS the electric field data of EDI, which measures the drift velocity of artificially injected electron beams, are often not available due to beam scattering.

The wave packets of magnetic and perpendicular electric field fluctuations observed by SC3 are shown in Fig. 2. The magnetic fluctuations are subtracted from the background magnetic field which is calculated as a moving average of $10 \mathrm{~min}$. As shown in Figs. 1g-k, the field fluctuations start from $\sim 21: 25 \mathrm{UT}$, with those perpendicular to $\boldsymbol{B}_{0}$ (almost corresponding to the $Y$ and $Z$ components) fluctuating more than the field-aligned fluctuations. The Poynting flux is calculated from the fluctuations of magnetic and perpendicular electric fields $\left(\boldsymbol{S}=\boldsymbol{d} \boldsymbol{E}_{\perp} \times \boldsymbol{d B}\right)$ and is linearly-interpolated during the intervals when electric field data are missing. The most dominant component of the Poynting flux is the $X$ component, directed earthward on average. The flux is of the order of $10^{-4} \mathrm{~mW} / \mathrm{m}^{2}$ and $<1 \mathrm{~mW} / \mathrm{m}^{2}$ when mapped at an altitude of $100 \mathrm{~km}$ (assuming $B=50000 \mathrm{nT}$ ). Using magnetic field fluctuations at one spacecraft the Minimum Variance Analysis (MVA) is performed within a window of $5 \mathrm{~min}$ (Sonnerup and Cahill, 1967). The MV axis is considered to be the propagation vector if the wave is completely a transverse wave. The angle between the MV axis and the background field is defined as $\theta_{M V A}$. Between 21:30 UT and 21:35 UT, when the eigenvalue ratio $\left(\lambda_{\min } / \lambda_{\text {int }}\right)$ is relatively small, thus indicating a good MVA determination, $\theta_{M V A}$ is comparable to or less than $30 \mathrm{deg}$. The Poynting flux observed by SC1 (not shown) is consistent with the SC 3 observations, although electric field data of SC 1 often has large data gaps. The MVA of the other spacecraft also shows that the $\theta_{M V A}$ angle is less than $30 \mathrm{deg}$ (not shown).

Figures 3a-b show the Fast Fourier Transform (FFT) spectra of magnetic and electric field fluctuations during 21:2521:40 UT. Right-hand mode is dominant, as mentioned before. The peak frequency is around $\sim 0.004 \mathrm{~Hz}(250 \mathrm{~s})$, which is much lower than the ion cyclotron frequency: see the dotted vertical line of $\mathrm{O}^{+}$cyclotron frequency $(\sim 0.03 \mathrm{~Hz})$. It should be noted that the electric field fluctuations show much power even in the high frequency range. The perpendicular 


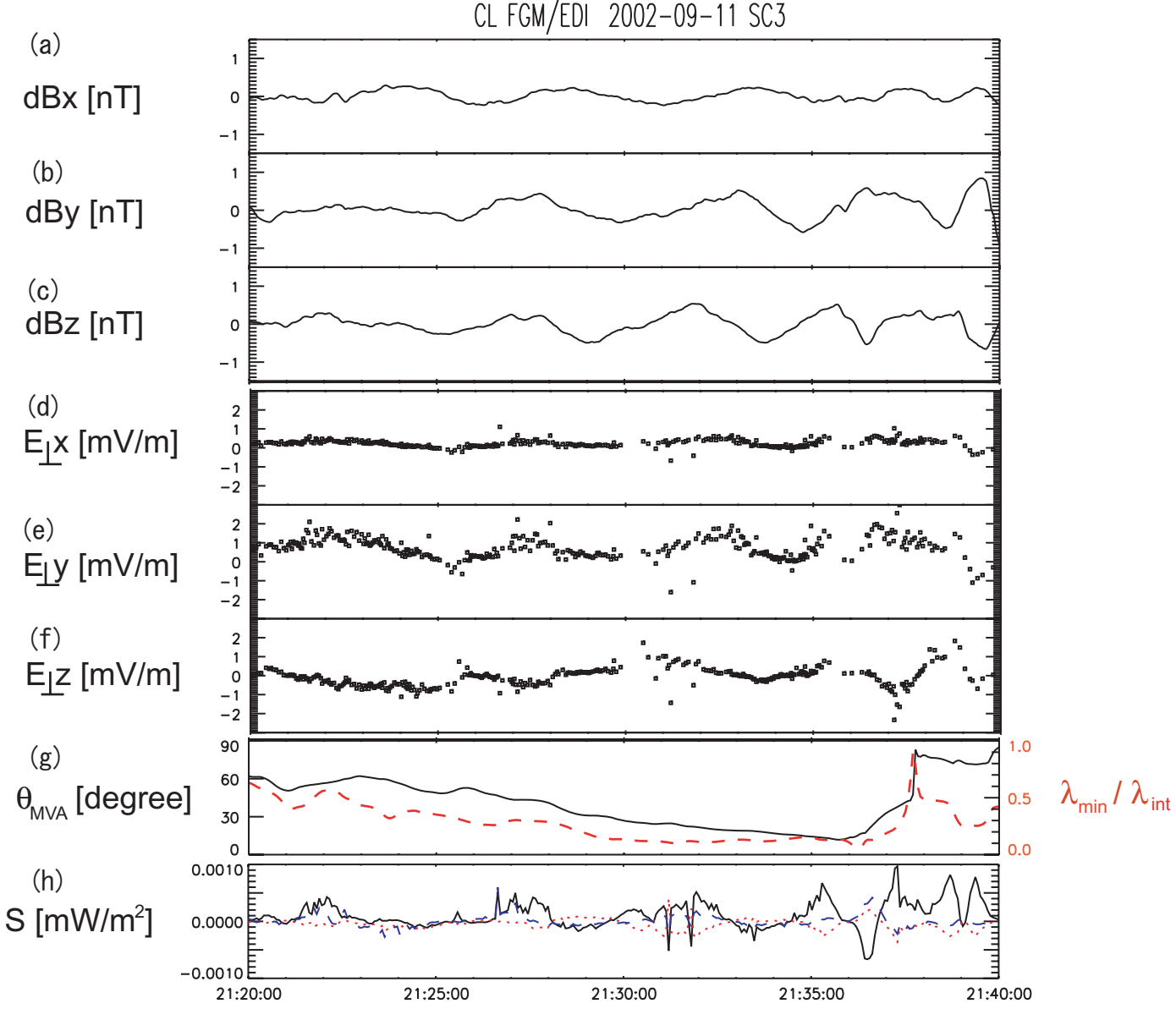

Fig. 2. Cluster SC 3 observation on 11 September 2002, of (a-c) three components of magnetic field after subtraction of the background magnetic field, $\boldsymbol{B}_{0}$ (10 min moving average), and (d-f) three components of the perpendicular electric field. (g) The angle between the background magnetic field and the minimum variance axis (black solid), and the eigenvalue ratio of minimum and intermediate (red dashed) are shown. (h) Poynting flux ( $S x$ : black solid, $S y$ : red dotted, $S z$ : blue dashed) is calculated from the magnetic and electric fields fluctuations and is linearly-interpolated during the intervals when electric field data are missing.

component of $|\Delta E| /|\Delta B|$ is shown against frequency in Fig. 3c. $\left|\Delta E_{\perp}\right| /\left|\Delta B_{\perp}\right|$ at the frequency of fluctuation peak is close to the local Alfvén velocity calculated from the average value of the proton density, $N_{P}\left(\sim 0.01 \mathrm{~cm}^{-3}\right)$, the $\mathrm{O}^{+}$ density, $N_{O^{+}}\left(\sim 0.016 \mathrm{~cm}^{-3}\right)$, and the total magnetic field intensity, $|B|(\sim 34 \mathrm{nT})$, during the interval. To show the effect that the $\mathrm{O}^{+}$admixture has on Alfvén velocity, the Alfvén velocity is also calculated only from $N_{P}$ and $|B|$.

\subsection{Statistical properties}

The wave characteristics of 10 events of the lobe magnetic field fluctuation are studied. In each event, the 10-min intervals, including most enhanced fluctuations, are selected in order to compare with the same FFT window.

Two examples of lobe Alfvén wave events are shown in Fig. 4. The proton energy-time diagrams clearly show PSlobe boundary crossings at 14:54 UT on 14 August 2001 and 12:40/12:43 UT on 10 October 2001 events, respectively. In the lobe, $\mathrm{O}^{+}$beams are observed in these two cases, and a similar $\mathrm{O}^{+}$signature is also detected in all 10 events (not shown). Magnetic and perpendicular electric field fluctuations are observed in the lobe before the PS-lobe boundary crossing. In the 14 August 2001 event, the electromagnetic fluctuations gradually increase until the PS-lobe boundary crossing. Before the PS-lobe boundary crossing in the 10 October 2001 event, intensification of the magnetic and electric field fluctuations is detected from $\sim 12: 30$ UT. These are typical features of the observed lobe wave events.

In order to investigate the propagation direction of these waves, we next conduct the MVA. MV axes of all events in the $X-Y$ and $X-Z$ planes are shown in Figs. 5a-b. The vector of the MV axis is calculated for every $4 \mathrm{~s}$ within a 5 -min sliding window by determining its polarity so as to have a positive $X$ component, and then averaged over each component during the 10-min interval of the event. If the MV axis changes dramatically during the interval, the vector of the 
MV axis is much smaller than unity: see one of the examples at $(X, Y, Z)=(-9.4,7.6,5.6) R_{E}$. The $\mathrm{MV}$ axis is almost along the background magnetic field, $\boldsymbol{B}_{0}$. This is consistent with transverse waves propagating along magnetic field lines. Average Poynting fluxes of all events in $X-Y$ and $X-Z$ planes are also shown in Figs. $5 \mathrm{c}$ and $5 \mathrm{~d}$. The direction of the Poynting flux is almost field-aligned and earthward in both hemispheres, assuming that the parallel electric field is negligible, i.e. $\boldsymbol{E} \cdot \boldsymbol{B}=0$. The results suggest that the wave energy in the near-tail $X=(-6,-20) R_{E}$ is transported mainly inward from the more distant tail. The absolute value of the Poynting flux ranges between about $2.9 \times 10^{-5}-6.7 \times 10^{-4} \mathrm{~mW} / \mathrm{m}^{2}$ (peak: $-7.1 \times 10^{-3}$ to $2.6 \times 10^{-2} \mathrm{~mW} / \mathrm{m}^{2}$ ), and amounts to $4.6 \times 10^{-2}-5.7 \times 10^{-1} \mathrm{~mW} / \mathrm{m}^{2}$ (peak: $\sim 10 \mathrm{~mW} / \mathrm{m}^{2}$ ) when mapped at an altitude of $100 \mathrm{~km}$, as shown before. This is roughly two orders of magnitude smaller than that of large amplitude Alfvén waves in the PSBL (Takada et al., 2005, and references therein). The difference of the Poynting flux between PSBL and lobe waves is consistent with this (2-3 orders difference) at Polar altitude (Keiling et al., 2005). In order to check the Alfvénic property, the FFT power ratio, $\left|\Delta E_{\perp}\right| \Lambda \Delta B_{\perp} \mid$, at the frequency peak is plotted in Fig. 5e against the local Alfvén velocity, $V_{A}$, calculated from $N_{P}$, $N_{O^{+}}$, and $|B|$. As with the PSBL waves (Wygant et al., 2000; Angelopoulos et al., 2002), the $\left|\Delta E_{\perp}\right| /\left|\Delta B_{\perp}\right|$ is much larger than that expected for steady-state closure through typical ionospheric conductivities, i.e. $\Delta E / \Delta B=1 / \mu_{0} \Sigma_{P}$, where the $\Sigma_{P}$ is the height-integrated Pedersen conductivity, which should be $5-10 \mathrm{~S}$ in a region of active auroral electron precipitation. Since most points are far away from $1 / \mu_{0} \Sigma_{P}$ yet within $\pm 50 \%$ of $V_{A}$, the wave looks like an Alfvén wave. The Alfvén velocity is not so high in these events $(\sim 1000$ $3000 \mathrm{~km} / \mathrm{s}$ ) because of the $\mathrm{O}^{+}$density as shown in Fig. $5 \mathrm{f}$, and the $\mathrm{O}^{+}$density is often much higher than the proton density.

All the selected lobe wave events occurred during the existence of an $\mathrm{O}^{+}$beam with $N_{O^{+}} \geq N_{P}$. It brings up the question of whether a necessary condition for lobe wave generation is the rich $\mathrm{O}^{+}$plasma. To clarify the role of $\mathrm{O}^{+}$beams, we searched again for lobe wave events without $\mathrm{O}^{+}$beams, neglecting the criterion of EDI electric field data availability. Only one example was found during summer 2001 and 2002, which is shown in Fig. 6. Magnetic field fluctuations are present in the lobe during an enhanced proton density interval at 15:00-15:20 UT and weak fluctuations are also seen at 15:35-15:45 UT. The PSBL/lobe crossings in this event are around 15:25-15:35 UT with broad-band electrostatic emissions (e.g. Kojima et al., 1997) and around 15:45 UT (before the PSBL ion beam detection) with an enhancement of the curlometer (Chanteur, 1998) current (not shown). In this case we cannot confirm whether the ratio $\left|\Delta E_{\perp}\right| /\left|\Delta B_{\perp}\right|$ corresponds to the Alfvén velocity, because no electric field data are available. However, wave characteristics, such as the predominance of the transverse components, and similar amplitudes and frequencies, suggest a similarity of the wave

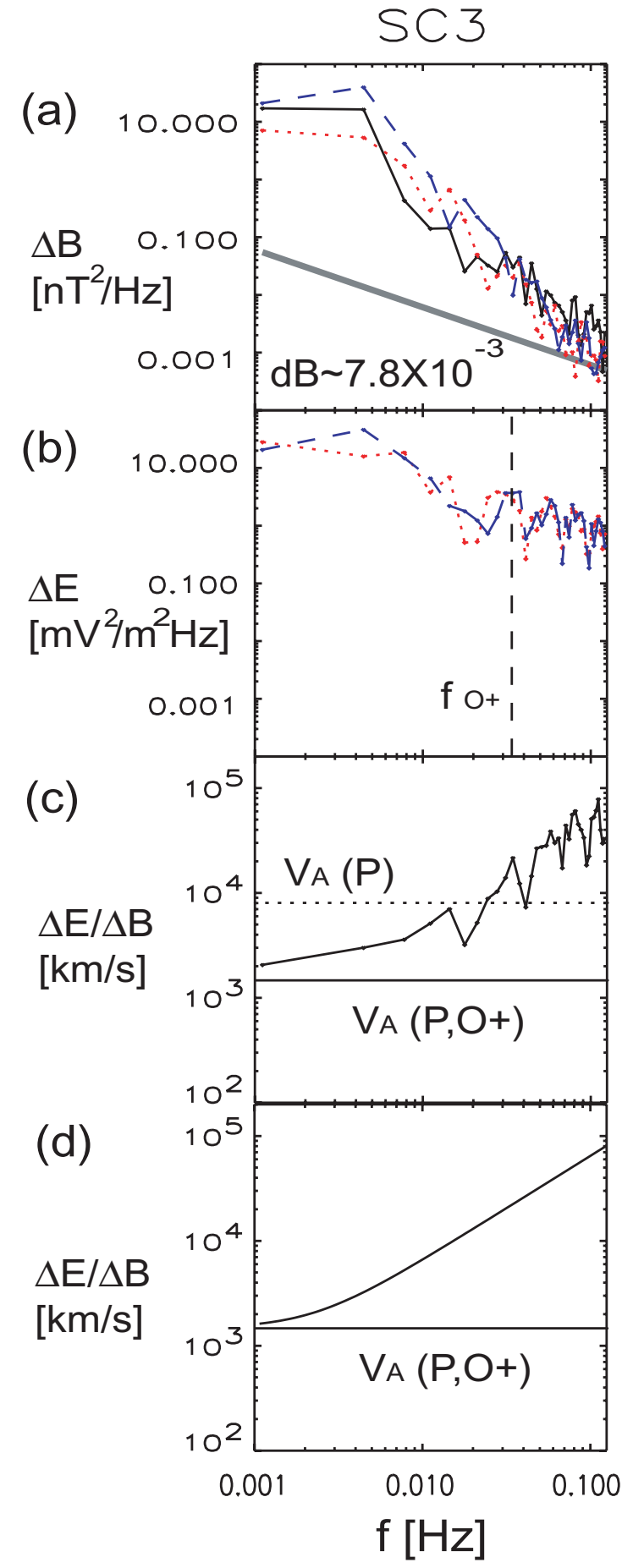

Fig. 3. (a) Wave power of magnetic field (C: black solid, RH: blue dashed, LH: red dotted) and (b) electric field plotted against the frequency. (c) Ratio of electric to magnetic field fluctuations in the unit of velocity versus frequency. Horizontal lines show the Alfvén velocity calculated from the average $|B|, N_{P}+N_{O+}$ (solid), and the average $|B|, N_{P}$ (dotted). (d) Solid curve shows the dispersion relation of KAW (see description in Sect. 3). All of spectra are calculated during 21:25-21:40 UT on 11 September 2002. 

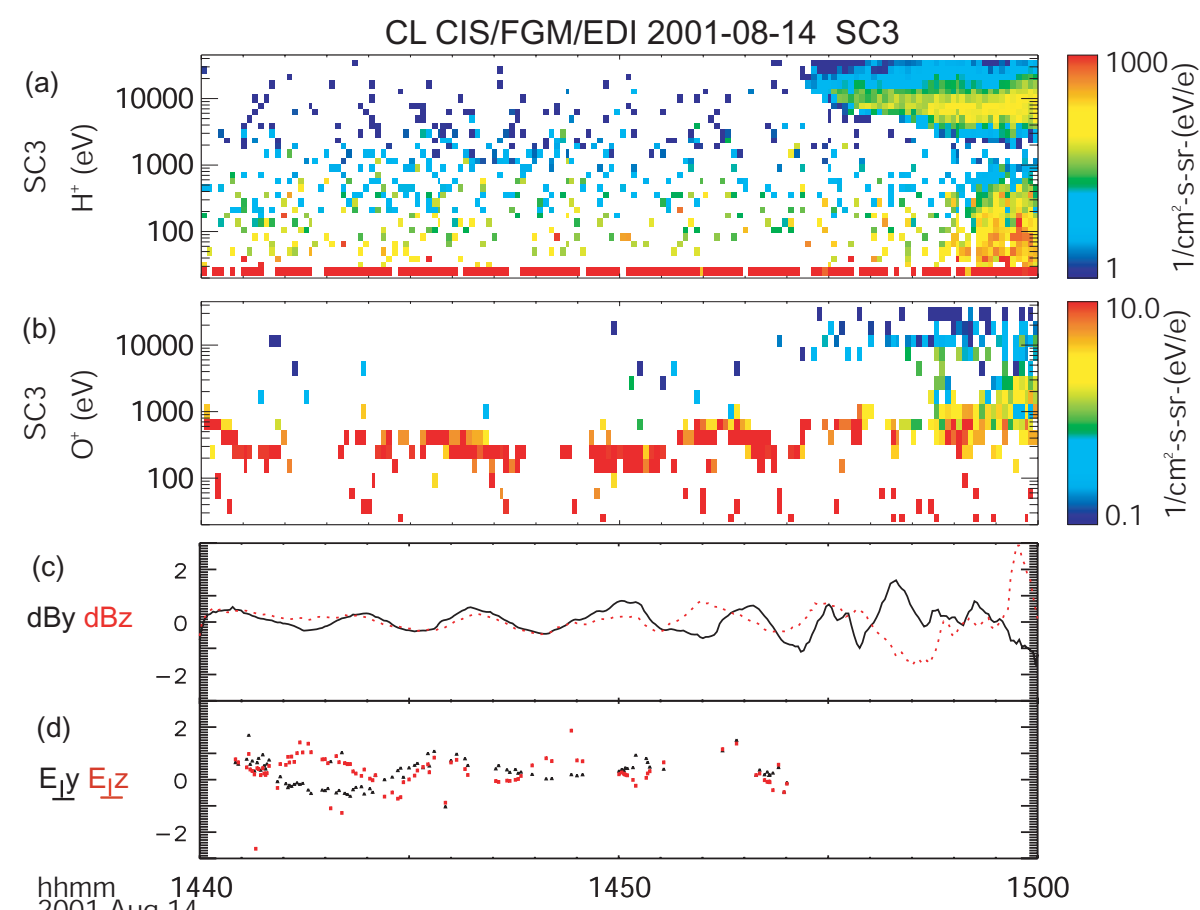

2001 Aug 14 CL CIS/FGM/EDI 2001-10-10 SC3
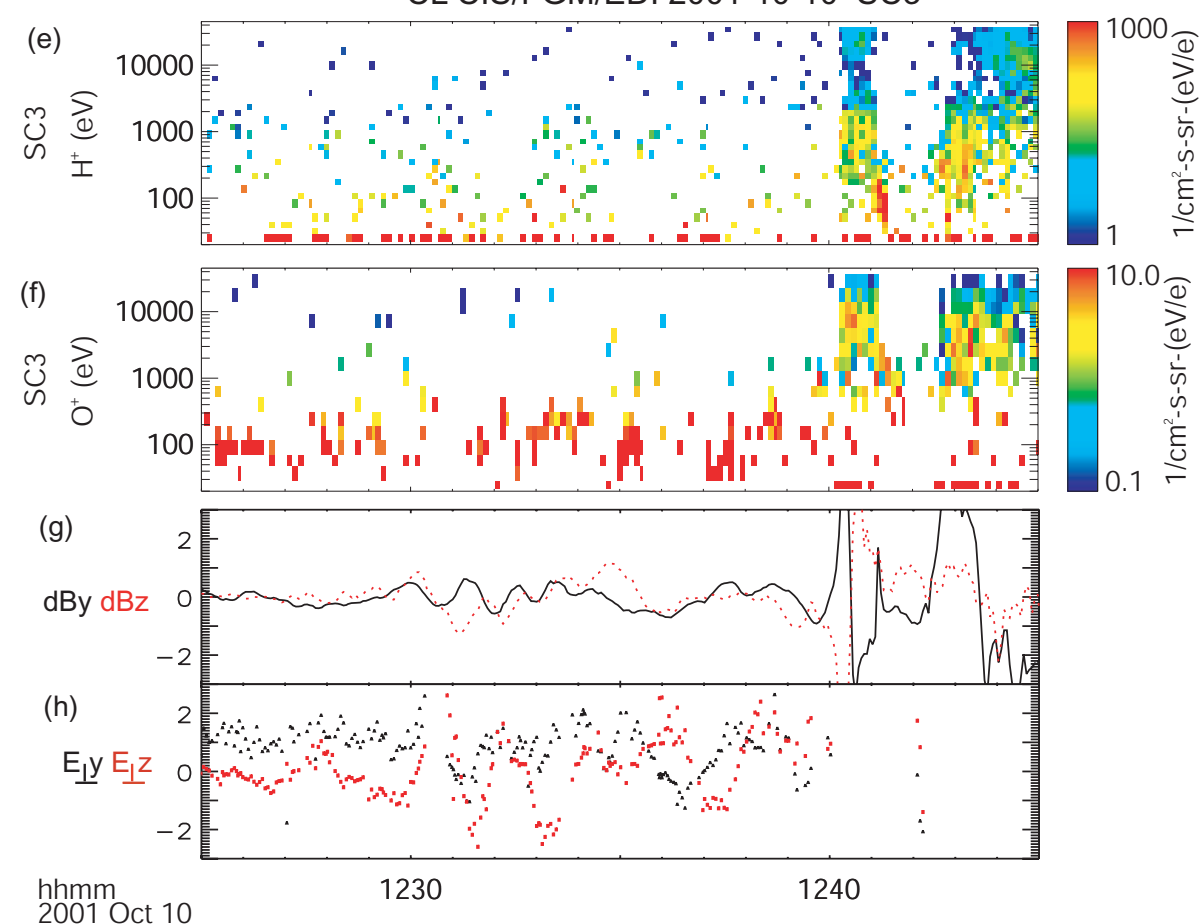

Fig. 4. Cluster SC3 observation on 14 August 2001 and 10 October 2001. Energy-time diagram of (a, e) proton and (b, f) $\mathrm{O}^{+}$are shown in color scales. (c, g) $d B y$ (black solid) and $d B z$ (red dotted) after subtraction of $\boldsymbol{B}_{0}$, and (d, h) $E_{\perp} y$ (black) and $E_{\perp} z$ (red) are shown.

modes detected. This one counter-example, at least, suggests that the presence of $\mathrm{O}^{+}$is not a necessary condition for tail waves.
Next, we check the global magnetospheric properties during the lobe wave events. Three parameters are chosen to see the effects of potentially important conditions for lobe wave generation and propagation: $D_{s t}$ for the supply of $\mathrm{O}^{+}$, 

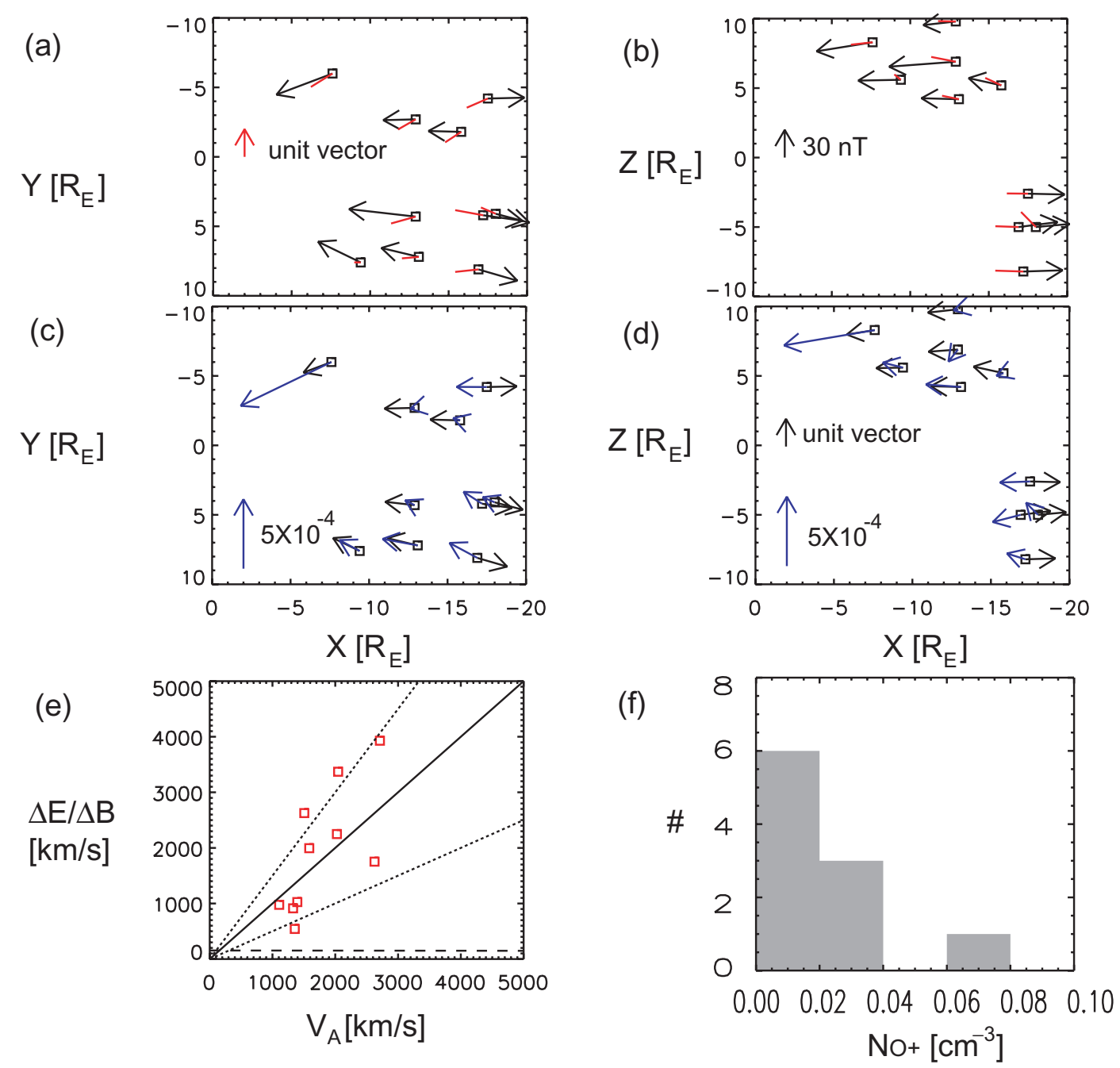

Fig. 5. The MV axis (red lines) distribution in (a) $X-Y$ and (b) $X-Z$ planes. Lines are adjusted to direct toward positive $X$ since MVA includes the ambiguity about the polarity. Black arrows are the vector of background magnetic field at the point. The Poynting flux (blue arrows) are shown as vector in (c) $X-Y$ and (d) $X-Z$ planes. Black arrows are the unit vector of background magnetic field at the point in (c-d). (e) $\left|\Delta E_{\perp}\right| \wedge \Delta B_{\perp} \mid$ plotted against local Alfvén velocity. Solid lines mark the range of $\pm 50 \%$ values of $V_{A}$. Horizontal dashed line is the $1 / \mu_{0} \Sigma_{P}$ when $\Sigma_{P}$ is $5 \mathrm{~S}$. Histogram of $\mathrm{O}^{+}$density is shown in (f).

high-latitude ground magnetic horizontal or northward components for substorm-association, and solar wind velocity for the KHI near the magnetopause. Figures 7a-i show the three parameters during the ten lobe wave events. As for the magnetic storm condition, 8 events occur during the recovery phase and one event (13 August 2001) is in the main phase. On 14 August 2001, a small storm has already recovered before the event. However, in all events, storm-associated $\mathrm{O}^{+}$ transport into the magnetosphere is possible (e.g. Daglis and Axford, 1996; Nosé et al., 2001). $B_{H} / B_{X}$ at high latitude stations are shown in the second panel of Figs. 7a-i (e.g. Yumoto et al., 2001). In all events the waves appear (dashed vertical lines) during an enhancement of the auroral electrojet, i.e. during the expansion or recovery phases of substorms. The green dashed lines also mark the start time of magnetic field fluctuations, which are far from the PS-lobe boundary crossing and are not selected for our 10 events. The PS-lobe boundary crossing (solid lines) is considered to be related to the expansion/thinning of the plasma sheet (e.g. Baumjohann et al., 1992) and is also seen during the recovery phase. Solar wind speed during these events is distributed between $400-700 \mathrm{~km} / \mathrm{s}$ and is not large $(<500 \mathrm{~km} / \mathrm{s})$ in 7 events out of 10. Pc3-5 ULF pulsations observed on the ground and in the magnetosphere are strongly enhanced under the fast solar wind of $>500 \mathrm{~km} / \mathrm{s}$ and are explained to be generated by KHI (Junginger and Baumjohann, 1988; Engebretson et al., 1998, and references therein). These results suggest that the lobe waves are mainly substorm-associated, rather than KHI-associated, since the wave appearance corresponds to auroral electrojet enhancements and is not biased 

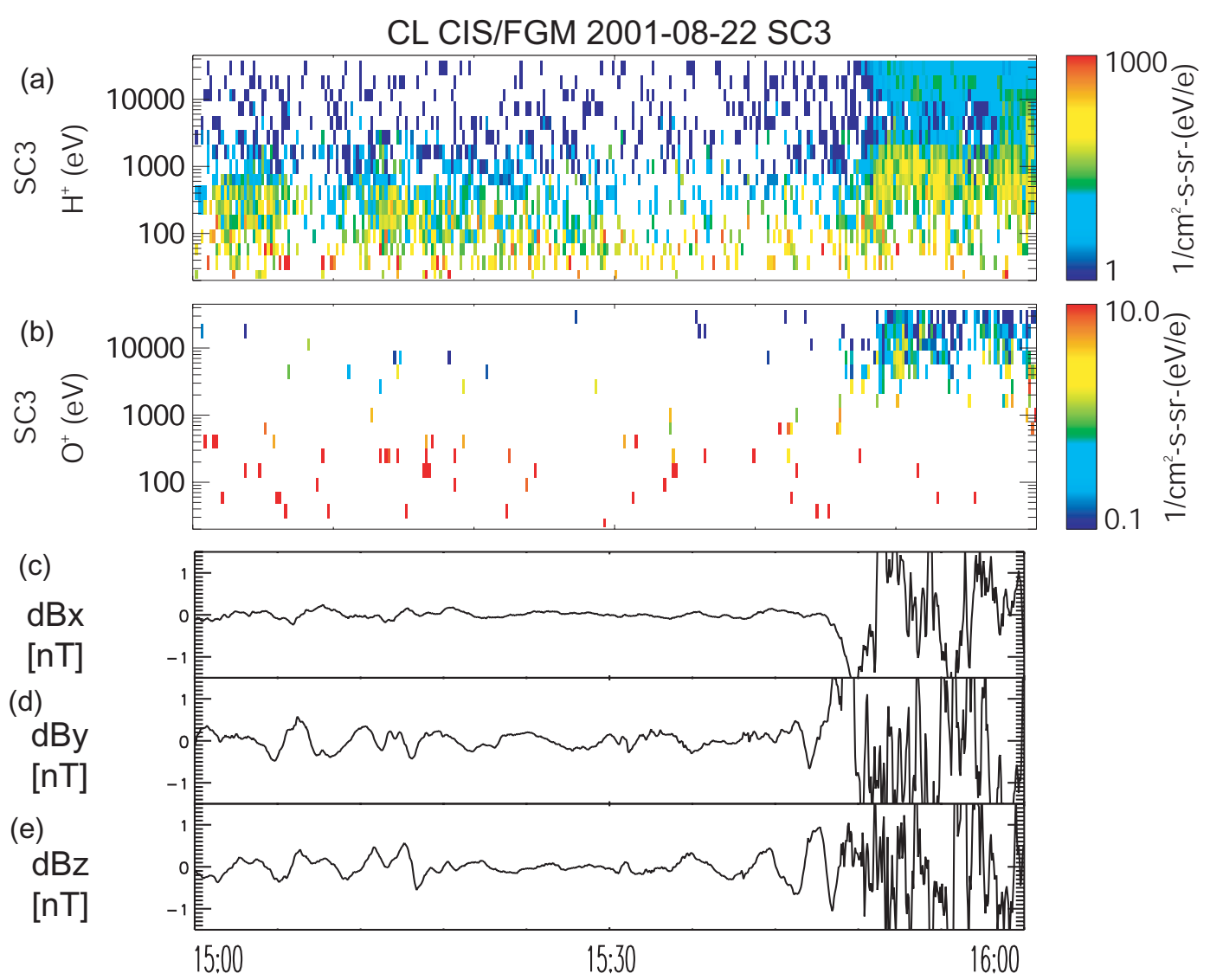

Fig. 6. Cluster SC3 observation on 22 August 2001. Top two panels show energy-time diagrams of (a) proton and (b) $\mathrm{O}^{+}$. (c-e) Magnetic field fluctuations after 10-min moving average subtraction are shown.

toward high solar wind velocity. Although it may be possible to be KHI-associated waves during fast solar wind condition, we cannot confirm the possibility in this study. The dense proton event shown in Fig. 7j, took place during a nonstorm period, as expected from the absence of $\mathrm{O}^{+}$. Similar to the other events, it occurred during an enhanced auroral electrojet, however, there was also a high solar wind velocity $(>600 \mathrm{~km} / \mathrm{s})$. Therefore, we cannot rule out the possibility of $\mathrm{KHI}$, that is, of an outer source for this event and three events of 10 (Figs. 7c, d and h).

\section{Discussion}

The relation, $\left|\Delta E_{\perp}\right| \Lambda \Delta B_{\perp} \mid \sim V_{A} \propto B / \sqrt{N_{P}+16 N_{O+}}$, is statistically satisfied for the observed waves, as shown in Fig. 5e. Combining with $S_{\|}=\Delta E_{\perp} \cdot \Delta B_{\perp}$, the magnetic field fluctuations are written as $\Delta B_{\perp}^{2} \propto \sqrt{N_{P}+16 N_{O+}} S_{\|} / B$. Since the lobe waves of our events are observed only during a "dense plasma" period, $\sqrt{N_{P}+16 N_{O+}}$ has a lower limit. On the other hand, the magnetic field fluctuations of the observed lobe waves were in general weak and did not exceed a peak-to-peak amplitude of $\sim 4 \mathrm{nT}$. Thus, we obtain a limi- tation of $S_{\|}<\max \left(\Delta B_{\perp}^{2}\right) / \min \left(\sqrt{N_{P}+16 N_{O+}}\right)$, which means the Poynting flux of the observed lobe waves were limited independent of the plasma condition. Note that due to our lobe criterion, $N_{P}<0.03 \mathrm{~cm}^{-3}$, some dense proton lobe events without $\mathrm{O}^{+}$beams may have been eliminated. Therefore, in the case that the $\mathrm{O}^{+}$ion is absent and the proton density is same, the Alfvén velocity increases and $\Delta B_{\perp}$ drops down to a criteria value in this study (in general, noise level), due to a limited Poynting flux. This could be one of the reasons why the lobe waves were accompanied by $\mathrm{O}^{+}$beams.

Particle instruments have limitations for density measurement because of the limited energy range and 1-count level of detectors. The Whisper instrument (Whisper of High frequency and Sounder for Probing Electron density by Relaxation) (Décréau et al., 2001) on board Cluster provides the spectrum of natural plasma emissions in the frequency band from $2-80 \mathrm{kHz}$ and the electron densities determined via the relaxation sounder (4-83 kHz) (Trotignon et al., 2001). Since the plasma frequency in the lobe is larger than the cyclotron frequency, the upper-hybrid frequency is close to the electron plasma frequency, which should be in the range of frequencies covered. Unfortunately, the total ion density in our cases is around $0.01-0.2 \mathrm{~cm}^{-3}\left(\omega_{p e} \sim 0.9-4 \mathrm{kHz}\right)$, even during the 


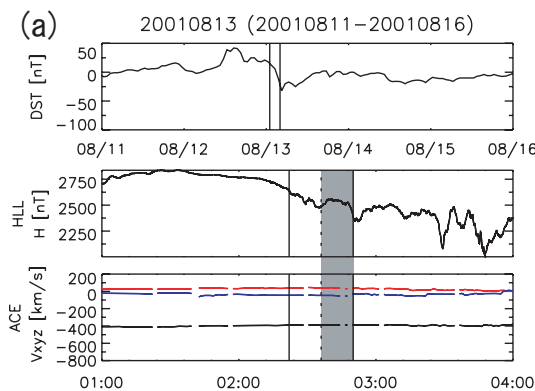

(b)
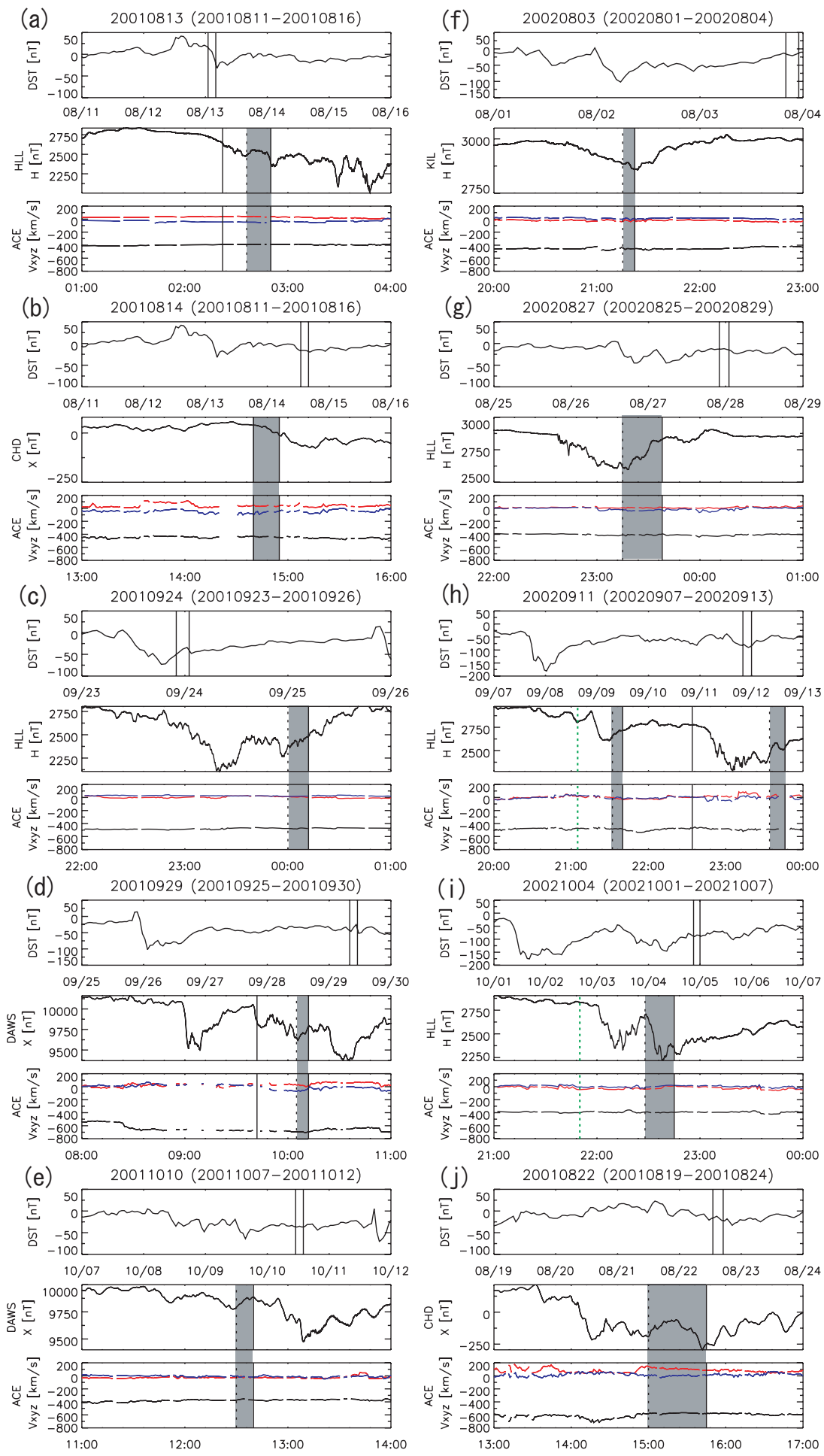

Fig. 7. Stack plots of $D_{s t}, H$ or $X$ component from ground magnetometers, time-shifted solar wind velocity (ACE). Two vertical lines in Dst show the time interval of ground and solar wind data ( $V x$ : black, $V y$ : red, $V z$ : blue). The vertical lines in ground and solar wind data mark the appearance of lobe fluctuations (black dashed) and PS-lobe boundary crossings (solid). For comparison, green dashed lines mark the time of non-selected fluctuation events. Selected event intervals are gray-shaded. Positions of ground stations are following: Hella/Island (HLL: CGMlat. 64.37, CGMlon. 67.60), Kilpisjärvi/Finland (KIL: CGMlat. 65.90, CGMlon. 103.93), Chokurdakh/Russia (CHD: CGMlat. 64.67, CGMlon. 212.12), and Dawson/Canada (DAWS: CGMlat. 65.92, CGMlon. 273.16). 
rich $\mathrm{O}^{+}$ion events and often out of instrument range. In order to assess the possibility of density underestimation by a particle detector, however, we can check if a lower cutoff at the electron plasma frequency is absent in the range of the instrument, suggesting the existence of a cutoff below the limit. In one case (24 September 2001), the total ion density is in the corresponding frequency range of the Whisper instrument, and the total density observed by CIS almost equals the estimated electron density by the relaxation sounder. In the other 9 cases, the spectra at least deny the possibility of higher electron density. Therefore, we think that the density estimation capability of particle instruments is enough to calculate the Alfvén velocity.

In general, there are two external wave sources, such as the magnetopause/magnetosheath (outer source) and the PSBL/PS (inner source). The close association with substorms shown in all the cases suggests an inner source, although the selected intervals within $30 \mathrm{~min}$ of PSBL/lobe crossings are preferable for the wave related to the inner source. This is consistent with the results of Keiling et al. (2005), where the lobe Alfvén waves started to be observed at substorm onset. In the PSBL, the low-frequency waves are often detected as KAW by Geotail (Angelopoulos et al., 2002) and by Polar (Wygant et al., 2002). The leakage of PSBL waves to the lobe is plausible to explain the lobe wave features consistent with the KAW-like feature discussed later. In the magnetotail waveguide model (Wright et al., 1999; Allan and Wright, 2000), however, the perpendicular wave number of the mode-converted Alfvén wave decreases sharply from the PSBL to the lobe $\left(k_{z} \sim 0\right)$. After the wave appearance, ion beams are observed in all events during the PSBL crossing, which shows the possibility that the ion beams already exist in the PSBL. Thus, the wave generation might be associated with magnetic reconnection or an ion beam instability in the PSBL. The event on 10 October 2001, shown in Fig. 4, is a good example to judge this view. The event was studied in detail by Nakamura et al. (2004). At the time of the lobe wave appearance, Geotail started to observe PSBL ion beams in the opposite hemisphere (see their Fig. 4). This suggests that PSBL ion beams are active during the near-PSBL lobe wave. There are two candidates for the lobe waves: waves generated by the reconnection process and/or the release of a plasmoid (e.g. Siscoe, 1969; Hones et al., 1987; Allan and Wright, 2000) or leakage of KAW from the PSBL. Allan and Wright $(1998,2000)$ theoretically suggest that the large Alfvén velocity gradient in the tail configuration converts fast mode (compressional) waves through the boundary into Alfvén waves with a phasemixing process. The warm plasma in the PSBL would ensure that the waves would have some kinetic characteristics, whereas shear Alfvén waves would be proceeded in the lobe. However, specifying the generation mechanism of the lobe Alfvén wave is beyond the scope of this paper.

In low $\beta(\sim 0.001)$ conditions, the obliquely propagating Alfvén wave works as a KAW (Lysak and Lotko, 1996).
In Fig. 3d, the dispersion relation is depicted as a solid curve (e.g. Stasiewicz et al., 2001). In order to calculate the dispersion relation, we use the average $V_{A}, T e \sim 1 / 7<T p>$ (Baumjohann et al., 1989), and $V s=38 \mathrm{~km} / \mathrm{s}$ (plasma structure velocity with respect to the spacecraft). The largest velocity along the wave propagation direction is selected as $V s$ among the following: plasma sheet moving velocity, $V_{\mathrm{PSBL}} \sim 100 \mathrm{~km} / \mathrm{s}$ (parallel component, $V_{\mathrm{PSBL} \|}<30 \mathrm{~km} / \mathrm{s}$ ), average $\mathrm{O}^{+}$beam velocity $(\sim 38 \mathrm{~km} / \mathrm{s})$ and spacecraft velocity (less than $2 \mathrm{~km} / \mathrm{s}$ ). The plasma sheet moving velocity is calculated at the PS-lobe boundary crossing at 21:40 UT, using four spacecraft timing analysis (abrupt $|B|$ decrease). The curve of $\Delta E / \Delta B$ against the frequency looks very similar to the observational curve in Fig. 3c. However, we cannot confirm this property because the power of magnetic fluctuations in the higher frequency range approach the digital resolution of the instrument $\left(d B=7.8 \times 10^{-3} \mathrm{nT}\right.$, see Balogh et al., 2001). It should be noted that the intermittent high-frequency fluctuations of the electric field might be manifestations of the KAW.

Most of the lobe wave events are related to rich $\mathrm{O}^{+}$conditions. The $\mathrm{O}^{+}$ions are transported from the ionosphere to the magnetotail lobe (e.g. Chappell et al., 1987; Lennartsson, 1994; Seki et al., 1998). In the lobe region, the energy of $\mathrm{O}^{+}$beam in our events is between $100 \mathrm{eV}$ and $1 \mathrm{keV}$ and occasionally more energized. An energization process can occur very close to the PSBL (Hirahara et al., 1994) and may be related to the KAW or an ion beam instability in the PSBL. Another energization process (mainly perpendicular acceleration) is related to lobe fluctuations. This is because the perpendicular velocity increases so as to correspond to the perpendicular electric field fluctuations (Sauvaud et al., 2004; Sergeev et al., 2005). A parallel acceleration due to the ponderomotive force of lobe waves is theoretically suggested (Allan, 1993; Allan and Wright, 2000). The in-situ Poynting flux of lobe waves is quite lower than that in the PSBL, but the cross-sectional area of the lobe is much larger than that of the PSBL. If the non-visible fluctuations, i.e. which are observationally too small fluctuations fill the whole lobe in the case of $100 \%$ proton plasma, this acceleration mechanism might not be negligible in addition to the cusp/cleft acceleration (e.g. Bouhram et al., 2002; Bogdanova et al., 2005). However, quantitative evaluation of the acceleration by ponderomotive force is for future work due to the lack of wave observations in the whole lobe.

As suggested in our study, lobe waves propagate earthward. It may finally reach the ionosphere, i.e. the polar cap region. Yagova et al. $(2002,2004)$ recently reported that ULF waves in the polar cap behave independently from wave activity in the cusp or auroral regions. The coherence of waves is high throughout the polar cap, while the correlation between auroral and polar cap is found to be poor. They discuss as one of the possibilities that the source of such waves is the tail lobe, although lobe waves in this study are originally associated with the substorms. However, the ULF waves in the 
polar cap, different from the auroral region waves, may be the result of the different propagation speeds of waves $\left(V_{A}\right)$ between the lobe and the PSBL. In addition, the PSBL waves are also absorbed or weakened via auroral electron acceleration (e.g. Keiling et al., 2003). The wave property/timing between auroral electrojet and polar cap should be different on the ground.

\section{Summary}

Low-frequency electromagnetic waves in the lobe are investigated using Cluster magnetic field, electric field, and particle data. The electromagnetic fluctuations close to the PSBL show an Alfvénic characteristic, i.e. $\Delta E / \Delta B$ is close to the Alfvén velocity. The waves propagate almost along field lines waves in the tail PSBL betweenand on average carry their Poynting flux $\left(2.9 \times 10^{-5}-6.7 \times 10^{-4} \mathrm{~mW} / \mathrm{m}^{2}\right.$ in situ $)$ toward the Earth. The Poynting flux is roughly two orders of magnitude smaller than the typical value in the PSBL. Most of lobe waves are associated with $\mathrm{O}^{+}$beams, which decrease the local Alfvén velocity, increase $\Delta B$, and thus make the waves detectable with the instrument used, rather than generate them locally. As all wave events are observed under the auroral electrojet enhancements when the PSBL ion beam ejection is active, but not necessarily during high speed solar wind, the generation mechanism of these waves is considered to be associated with an inner source, such as some instabilities near a reconnection site or the leakage of kinetic Alfvén waves in PSBL.

Acknowledgements. We thank H.-U. Eichelberger for helping in the Cluster data analysis for making available data used in this study. The authors thank the SAMNET team and Finnish Meteorological Institute for magnetometer data. SAMNET is a PPARC National Facility operated by Lancaster University. We also thank the Space Environment Research Center, Kyushu University for the usage of the CPMN magnetometer data and acknowledge CARISMA and SSDP teams for making available the CANOPUS magnetometer data used in this study. The operation of the CARIMSA magnetometer array and the SSDP is funded by the Canadian Space Agency. ACE spacecraft data are provided by D. J. McComas (SWRI) and available on CDAWeb. The work by M. Volwerk was financially supported by the German Bundesministerium für Bildung und Forschung and the Zentrum für Luft- und Raumfahrt under contract 50 OC 0104

Topical Editor T. Pulkkinen thanks W. Allan and another referee for their help in evaluating this paper.

\section{References}

Akimoto, K., Gary, S. P., and Omidi, N.: Electron/ion whistler instabilities and magnetic noise bursts, J. Geophys. Res., 92, $11209-11214,1987$.

Allan, W.: Plasma energization by the Ponderomotive force of magnetospheric standing Alfvén waves, J. Geophys. Res., 98, $11383-11390,1993$.
Allan, W. and Wright, A. N.: Hydromagnetic wave propagation and coupling in a magnetotail waveguide, J. Geophys. Res., 103, 2359-2368, 1998.

Allan, W. and Wright, A. N.: Magnetotail waveguide: Fast and Alfvén waves in the plasma sheet boundary layer and lobe, J. Geophys. Res., 105, 317-328, 2000.

Angelopoulos, V., Elphic, R. C., Gary, S. P., and Huang, C. Y.: Electromagnetic instabilities in the plasma sheet boundary layer, J. Geophys. Res., 94, 15373-15 383, 1989.

Angelopoulos, V., Chapman, J. A., Mozer, F. S., Scudder, J. D., Russell, C. T., Tsuruda, K., Mukai, T., Hughes, T. J., and Yumoto, K.: Plasma sheet electromagnetic power generation and its dissipation along auroral field lines, J. Geophys. Res., 107(A8), 1181, doi:10.1029/2001JA900136, 2002.

Ballatore, P., Lanzerotti, L. J., and Maclennan, C. G.: Multistation measurements of Pc5 geomagnetic power amplitudes at high latitudes, J. Geophys. Res., 103, 29 455-29465, 1998.

Balogh, A., Carr, C. M., Acuna, M. H., Dunlop, M. W., Beek, T. J., Brown, P., Fornacon, K.-H., Georgescu, E., Glassmeier, K.H., Harris, J., Musmann, G., Oddy, T., and Schwingenschuh, K.: The Cluster magnetic field investigation: Overview of in-flight performance and initial results, Ann. Geophys., 19, 1207-1217, 2001.

Bauer, T. M., Baumjohann, W., Treumann, R. A., Sckopke, N., and Lühr, H.: Low-frequency waves in the near-Earth plasma sheet, J. Geophys. Res., 100, 9605-9617, 1995.

Baumjohann, W., Paschmann, G., and Cattell, C. A.: Average plasma properties in the central plasma sheet, J. Geophys. Res. 94, 6597-6606, 1989.

Baumjohann, W., Paschmann, G., and Nagai, T.: Thinning and expansion of the substorm plasma sheet, J. Geophys. Res., 97, 17 173-17 175, 1992.

Bogdanova, Y. V., Klecker, B., Paschmann, G., Kistler, L. M., Mouikis, C., Moebius, E., Rème, H., Bosqued, J. M., Dandouras, I., Sauvaud, J. A., Cornilleau-Wehrlin, N., Laakso, H., Korth, A., Bavassano-Cattaneo, M. B., Marcucci, M. F., Phan, T., Carlson, C., Parks, G., McFadden, J. P., McCarthy, M., and Lundin, R.: Investigation of the source region of ionospheric oxygen outflow in the cleft/cusp using multi-spacecraft observations by CIS onbouard Cluster, Adv. Space Res., 34, 2459-2464, 2005.

Bouhram, M., Dubouloz, N., Malingre, M., Jasperse, J. R., Pottelette, R., Senior, C., Delcourt, D., Carlson, C. W., Roth, I., Berthomier, M., and Sauvaud, J.-A.: Ion outflow and associated perpendicular heating in the cusp observed by Intervall Auroral Probe and fast auroral snapshot, J. Geophys. Res., 107, 1023, doi:10.1029/2001JA000091, 2002.

Cattell, C. A., Mozer, F. S., Anderson, R. R., Hones Jr., E. W., and Sharp, R. D.: ISEE observations of the plasma sheet boundary, plasma sheet, and neutral sheet: 2. Waves, J. Geophys. Res., 91, 5681-5688, 1986.

Chanteur, G.: Spatial interpolation for four spacecraft: Theory, in: Analysis Methods for Multi-Spacecraft Data, edited by: Paschmann, G. and Daly, P., 349-369, ESA, Noordwijk, 1998.

Chappell, C. R., Moore, T. E., and Waite Jr., J. H.: The ionosphere as a fully adequate source of plasma for the Earth's magnetosphere, J. Geophys. Res., 92, 5896-5910, 1987.

Chen, S.-H. and Kivelson, M. G.: On ultralow frequency waves in the lobes of the Earth's magnetotail, J. Geophys. Res., 96, 15 711-15 723, 1991. 
Daglis, I. A. and Axford, W. I.: Fast ionospheric response to enhanced activity in geospace: Ion feeding of the inner magnetotail, J. Geophys. Res., 101, 5047-5065, 1996.

Décréau, P. M. E., Fergeau, P., Krasnoselskikh, V., Le Guirriec, E., Lévêque, M., Martin, Ph., Randriamboarison, O., Rauch, J. L., Sené, F. X., Séran, H. C., Trotignon, J. G., Canu, P., Cornilleau, N., De Féraudy, H., Alleyne, H., Yearby, K., Mögensen, P. B., Gustafsson, G., André, M., Gurnett, D. C., Darrouzet, F., Lemaire, J., Harvey, C. C., Travnicek, P., and Whisper experimenters: Early results from the Whisper instrument on Cluster: An overview, Ann. Geophys., 19, 1241-1258, 2001.

De Keyser, J.: Magnetohydrodynamic wave mode conversion in the Earth's magnetotail, J. Geophys. Res., 105, 13 009-13 016, 2000.

Elphinstone, R. D., Hearn, D. J., Cogger, L. L, Murphree, J. S., Wright, A., Sandahl, I., Ohtani, S., Newell, P. T., Klumpar, D. M., and Shapshak, M.: The double oval UV auroral distribution: 2. The most poleward arc system and the dynamics of the magnetotail, J. Geophys. Res., 100, 12 093-12 102, 1995.

Engebretson, M., Glassmeier, K.-H., Stellmacher, M., Hughes, W. J., and Lühr, H.: The dependence of high-latitude Pc5 wave power on solar wind velocity and on the phase of high-speed solar wind streams, J. Geophys. Res., 103, 26 271-26 283, 1998.

Harrold, B. G., Goertz, C. K., Smith, R. A., and Hansen, P. J.: Resonant Alfvén wave heating of the plasma sheet boundary layer, J. Geophys. Res., 95, 15 039-15 046, 1990.

Hirahara, M., Nakamura, M., Terasawa, T., Mukai, T., Saito, Y., Yamamoto, T., Nishida, A., Machida, S., and Kokubun, S.: Acceleration and heating of cold ion beams in the plasma sheet boundary layer observed with Geotail, Geophys. Res. Lett., 21, 30033006, 1994.

Hones Jr., E. W., Anger, C. D., Birn, J., Murphree, J. S., and Cogger, L. L.: A study of a magnetospheric substorm recorded by the Viking auroral imager, Geophys. Res. Lett., 14, 411-414, 1987.

Junginger, H. and Baumjohann, W.: Dayside long-period magnetospheric pulsations: Solar wind dependence, J. Geophys. Res., 93, 877-883, 1988.

Keiling, A., Wygant, J. R., Cattell, C. A., Mozer, F. S., and Russell, C. T.: The global morphology of wave Poynting flux: Powering the aurora, Science, 299, 383-386, doi:10.1126/science.1080073, 2003.

Keiling, A., Parks, G. K., Wygant, J. R., Dombeck, J., Mozer, F. S., Russell, C. T., Streltsov, A. V., and Lotko, W.: Some properties of Alfvén waves: Observations in the tail lobes and the plasma sheet boundary layer, J. Geophys. Res., 110, A10S11, doi:10.1029/2004JA010907, 2005.

Kojima, H., Matsumoto, H., Chikuba, S., and Horiyama, S.: Geotail waveform observations of broadband/narrowband electrostatic noise in the distant tail, J. Geophys. Res., 102, 14 439-14455, 1997.

Lennartsson, O. W.: Tail lobe ion composition at energies of 0.1 to $16 \mathrm{keV} / \mathrm{e}:$ Evidence for mass-dependent density gradients, J. Geophys. Res., 99, 2387-2401, 1994.

Liu, W. W., Xu, B.-L., Samson, J. C., and Rostoker, G.: Theory and observation of auroral substorms: A magnetohydrodynamic approach, J. Geophys. Res., 100, 79-95, 1995.

Lysak, R. L. and Lotko, W.: On the kinetic dispersion relation for shear Alfvén waves, J. Geophys. Res., 101, 5085-5094, 1996.

Nakamura, R., Baumjohann, W., Nagai, T., Fujimoto, M., Mukai, T., Klecker, B., Treumann, R., Balogh, A., Rème, H., Sauvaud, J.
A., Kistler, L., Mouikis, C., Owen, C. J., Fazakerley, A. N., Dewhurst, J. P., and Bogdanova, Y.: Flow shear near the boundary of the plasma sheet observed by Cluster and Geotail, J. Geophys. Res., 109, A05204, doi:10.1029/2003JA010174, 2004.

Nosé, M., Ohtani, S., Takahashi, K., Lui, A. T. Y., McEntire, R. W., Williams, D. J., Christon, S. P., and Yumoto, K.: Ion composition of the near-Earth plasma sheet in storm and quiet intervals: Geotail/EPIC measurements, J. Geophys. Res., 106, 8391-8403, 2001.

Paschmann, G., Quinn, J. M., Torbert, R. B., Vaith, H., McIlwain, C. E., Haerendel, G., Bauer, O. H., Bauer, T., Baumjohann, W., Fillius, W., Förster, M., Frey, S., Georgescu, E., Kerr, S. S., Kletzing, C. A., Matsui, H., Puhl-Quinn, P., and Whipple, E. C.: The Electron Drift Instrument on Cluster: Overview of first results, Ann. Geophys., 19, 1273-1288, 2001.

Pilipenko, V. A., Watermann, J., Popov, V. A., and Papitashvili, V. O.: Relationship between auroral electrojet and Pc5 ULF waves, J. Atmos. Sol. Terr. Phys., 64, 183-201, 2002.

Rème, H., Aoustin, C., Bosqued, J. M., et al.: First multispacecraft ion measurements in and near the Earth's magnetosphere with the identical Cluster Ion Spectrometry (CIS) experiment, Ann. Geophys., 19, 1303-1354, 2001.

Sarafopoulos, D. V.: Long duration Pc5 compressional pulsations inside the Earth's magnetotail lobes, Ann. Geophys., 13, 926937, 1995.

Sarafopoulos, D. V. and Sarris, E. T.: Quiet-time Pc5 pulsations in the Earth's magnetotail: IMP-8, ISEE-1 and ISEE-3 simultaneous observations, Ann. Geophys., 12, 121-138, 1994.

Sauvaud, J.-A., Louarn, P., Fruit, G., Stenuit, H., Vallat, C., Dandouras, J., Rème, H., André, M., Balogh, A., Dunlop, M., Kistler, L., Möbius, E., Mouikis, C., Klecker, B., Parks, G. K., McFadden, J., Carlson, C., Marcucci, F., Pallocchia, G., Lundin, R., Korth, A., and McCarthy, M.: Case studies of the dynamics of ionospheric ions in the Earth's magnetotail, J. Geophys. Res., 109, A01212, doi:10.1029/2003JA009996, 2004.

Seki, K., Hirahara, M., Terasawa, T., Mukai, T., Saito, Y., Machida, S., Yamamoto, T., and Kokubun, S.: Statistical properties and possible supply mechanisms of tailward cold $\mathrm{O}^{+}$beams in the lobe/mantle regions, J. Geophys. Res., 103, 4477-4489, 1998.

Sergeev, V. A., Kubyshkina, M. V., Baumjohann, W., Nakamura, R., Amm, O., Pulkkinen, T., Angelopoulos, V., Mende, S. B., Klecker, B., Nagai, T., Sauvaud, J.-A., Slavin, J. A., and Thomsen, M. F.: Transition from substorm growth to substorm expansion phase as observed with a radial configuration of ISTP and Cluster spacecraft, Ann. Geophys., 23, 2183-2198, 2005.

Siscoe, G. L.: Resonant compressional waves in the geomagnetic tail, J. Geophys. Res., 79, 6482-6486, 1969.

Smith, R. A., Goertz, C. K., and Grossmann, W.: Thermal catastrophe in the plasma sheet boundary layer, Geophys. Res. Lett., 13, 1380-1383, 1986.

Smith, R. A., Goldstein, M. L., Sands, M. R., Lepping, R. P., Goertz, C. K., Harrold, B. G., Fitch, C. A., and Shan, L.-H.: Ultralow-frequency wave power in the magnetotail lobes: 1 . Relation to substorm onsets and the auroral electrojet index, Geophys. Res. Lett., 17, 1845-1848, 1990.

Sonnerup, B. U. Ö. and Cahill Jr., L. J.: Magnetopause structure and attitude from Explorer 12 observations, J. Geophys. Res., 72, 171, 1967.

Stasiewicz, K., Seyler, C. E., Mozer, F. S., Gustafsson, G., Pickett, 
J., and Popielawska, B.: Magnetic bubbles and kinetic Alfvén waves in the high-latitude magnetopause boundary, J. Geophys. Res., 106, 29503-29514, 2001.

Stern, D. P.: The electric field and global electrodynamics of the magnetosphere, Rev. Geophys. Space Phys., 17, 626-640, 1979.

Takada, T., Seki, K., Hirahara, M., Fujimoto, M., Saito, Y., Hayakawa, H., and Mukai, T.: Statistical properties of lowfrequency waves and ion beams in the plasma sheet boundary layer: Geotail observations, J. Geophys. Res., 110, A02204, doi:10.1029/2004JA010395, 2005.

Trotignon, J. G., Décréau, P. M. E., Rauch, J. L., Randriamboarison, O., Kransnoselskikh, V., Canu, P., Alleyne, H., Yearby, K., Le Guirriec, E., Séran, H. C., Sené, F. X., Martin, Ph., Lévêque, M., and Fergeau, P.: How to determine the thermal electron density and the magnetic field strength from the Cluster/Whisper observations around the Earth, Ann. Geophys., 19, 1711-1720, 2001.

Tsurutani, B. T., Richardson, I. G., Thorne, R. M., Butler, W., Smith, E. J., Cowley, S. W. H., Gary, S. P., Akasofu, S.-I., and Zwickl, R. D.: Observations of the right-hand resonant ion beam instability in the distant plasma sheet boundary layer, J. Geophys. Res., 90, 12 159-12 172, 1985.

Weatherwax, A. T., Rosenberg, T. J., Maclennan, C. G., and Doolittle, J. H.: Substorm precipitation in the polar cap and associated Pc5 modulation, Geophys. Res. Lett., 24, 579-582, 1997.

Wright, A. N., Allan, W., Elphinstone, R. D., and Cogger, L. L.: Phasemixing and phase motion of Alfvén waves on tail-like and dipole-like magnetic field lines, J. Geophys. Res., 104, 10159 $10175,1999$.
Wygant, J. R., Keiling, A., Cattell, C. A., Johnson, M., Lysak, R. L., Temerin, M., Mozer, F. S., Kletzing, C. A., Scudder, J. D., Peterson, W., Russell, C. T., Parks, G., Brittnacher, M., Germany, G., and Spann, J.: Polar spacecraft based comparisons of intense electric fields and Poynting flux near and within the plasma sheet-tail lobe boundary to UVI images: An energy source for the aurora, J. Geophys. Res., 105, 18 675-18 692, 2000.

Wygant, J. R., Keiling, A., Cattell, C. A., Lysak, R. L., Temerin, M., Mozer, F. S., Kletzing, C. A., Scudder, J. D., Streltsov, V., Lotko, W., and Russell, C. T.: Evidence for kinetic Alfvén waves and parallel electron energization at 4-6 $R_{E}$ altitudes in the plasma sheet boundary layer, J. Geophys. Res., 107(A8), 1201, doi:10.1029/2001JA900113, 2002.

Yagova, N. V., Lanzerotti, L. J., Villante, U., Pilipenko, V. A., Lepidi, S., Francia, P., Papitashvili, V. O., and Rodger, A. S.: ULF Pc5-6 magnetic activity in the polar cap as observed along a geomagnetic meridian in Antarctica, J. Geophys. Res., 107(A8), 1195, doi:10.1029/2001JA900143, 2002.

Yagova, N. V., Pilipenko, V. A., Lanzerotti, L. J., Engebretson, M. J., Rodger, A. S., Lepidi, S., and Papitashvili, V. O.: Two-dimensional structure of long-period pulsations at polar latitudes in Antarctica, J. Geophys. Res., 109, A03222, doi:10.1029/2003JA010166, 2004.

Yumoto, K. and the CPMN Group: Characteristics of Pi2 magnetic pulsations observed at the CPMN stations: A review of the STEP results, Earth Planets Space, 53, 981-992, 2001. 